\title{
Diagnostic Imaging Program
}

National Cancer Institute

\section{Source}

National Cancer Institute. Diagnostic Imaging Program. NCI Thesaurus. Code C16046.

(1) Plans and coordinates the development; (2) coordinates the clinical testing of new approaches in academia, industry, or in other parts of the federal government; (3) coordinates the development targeted to specific biochemical or physiological processes in cancer cells for better biologic insight into the physiology of human tumors; (4) encourages industrial commitment to the development and ultimate clinical testing relevant to cancer; (5) coordinates activities with other programs of the Institute, other federal agencies, and outside organizations; (6) coordinates the activities of the branches within the Prog ram for productive interactions and effective technology transfer; and (7) assesses the activities of the Program and advises the Division Director regarding scientific opportunities for the development of new approaches to the diagnosis and treatment of cancer. 